This item was submitted to Loughborough's Research Repository by the author.

Items in Figshare are protected by copyright, with all rights reserved, unless otherwise indicated.

\title{
Measuring the flow properties of small powder samples using an avalanche tester
}

PLEASE CITE THE PUBLISHED VERSION

http://dx.doi.org/10.1080/07373937.2015.1072093

PUBLISHER

(C) Taylor \& Francis

\section{VERSION}

AM (Accepted Manuscript)

\section{PUBLISHER STATEMENT}

This work is made available according to the conditions of the Creative Commons Attribution-NonCommercialNoDerivatives 4.0 International (CC BY-NC-ND 4.0) licence. Full details of this licence are available at: https://creativecommons.org/licenses/by-nc-nd/4.0/

\section{LICENCE}

CC BY-NC-ND 4.0

\section{REPOSITORY RECORD}

Jaggi, V., Mark Leaper, and Andrew J. Ingham. 2016. "Measuring the Flow Properties of Small Powder Samples Using an Avalanche Tester". figshare. https://hdl.handle.net/2134/20982. 


\title{
Measuring the flow properties of small powder samples using an avalanche tester
}

\author{
V.Jaggi $^{1}$, M.C. Leaper ${ }^{1}$ and A. Ingham ${ }^{2}$ \\ ${ }^{1}$ Chemical Engineering and Applied Chemistry, Aston University, Birmingham, UK, B7 4ET \\ ${ }^{2}$ Aston Pharmacy School, Aston University, Birmingham, UK, B7 4ET
}

Abstract - The feasibility of using a small-scale avalanche tester to measure the flow properties of pharmaceutical lactose powders was examined. The modes of behaviour observed in larger systems were displayed and showed a clear distinction between angular, free-flowing particles and more spherical particles of similar flow characteristics. Angular Lactohale LH100 particles showed slumping behaviour at a rotational frequency of $0.33 \mathrm{~Hz}$ which disappeared at higher frequencies. Spherical lactose powder with a similar flow function to LH100 only showed rolling behaviour under the same conditions, as did more cohesive powders LH200 and LH300. Further investigation of the LH100 data using Fast Fourier analysis showed that the slumping frequency was $1 / 10^{\text {th }}$ of the rotational frequency.

\section{INTRODUCTION}

Measuring the flow of properties of small amounts of powder is a significant challenge that needs to be addressed. Many methods of powder production in the pharmaceutical sector have been developed that produce materials in quantities significantly below the threshold required for conventional powder testing such as the Jenike shear cell; this restriction prevents the characterisation of bulk flow properties that are crucial to maintaining tablet die filling and tablet reproducibility. In the case of freeze-drying, high-value biological molecules are often dried to low-density powdered volumes for dispensing through weight. In response to this challenge, a powder tester has been developed [1], consisting of a small version of a rotating drum, to examine the dynamic flow properties of pharmaceutical powders in these small quantities. A small cylindrical vial containing powder is placed on a roller system which causes it to rotate at a set rotational speed. At low speeds, the powder forms a slope and particles form a cascading avalanche system, as shown by the red arrows in Figure 1. A camera follows the centre mass of the powder zone, with the position of this being recorded as $\mathrm{X}-\mathrm{Y}$ Cartesian coordinates (Figure 2). The resulting data points are analysed using a programme written in $\mathrm{C}++$ Sharp. Imaging is controlled through the use of backlit enclosure, ensuring that the image is consistently analysed. The position of the centre mass can be traced against time at a high sampling frequency. 


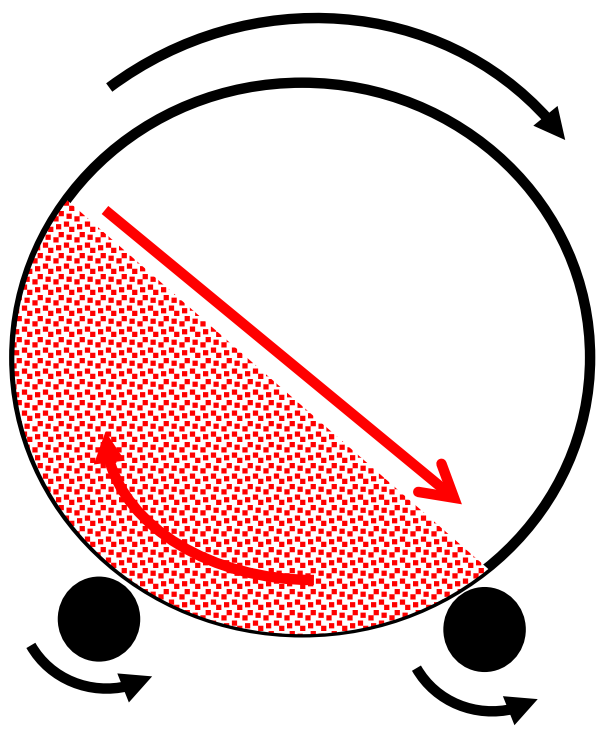

Figure 1: Schematic diagram of the Ingham Group avalanche tester, showing the rotation of the sample vial in black and the powder in red.

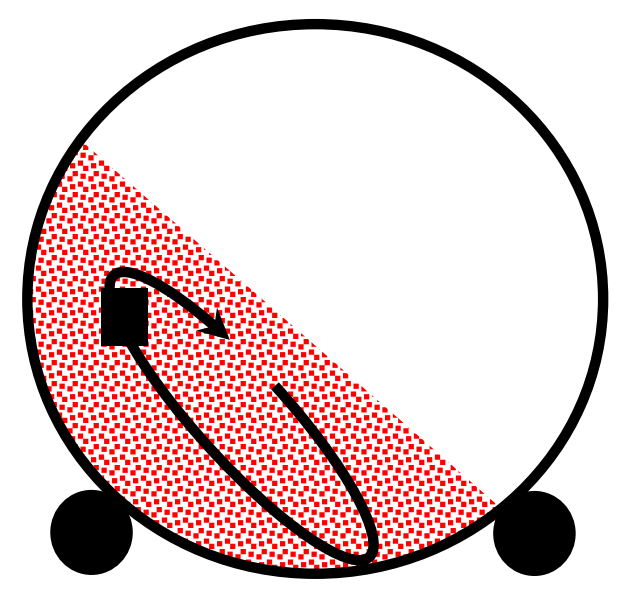

Figure 2: Schematic diagram of the Ingham Group avalanche tester, showing the rotation of the observed centre of mass of the powder.

This configuration makes it particularly attractive for small freeze-dried samples which are manufactured and stored in vials of controlled humidity and cannot undergo conventional testing, as well as those samples of high value where a significant mass is not available. This contrasts with other testers such as the Brookfield shear cell tester and the Freeman FT4 dynamic tester, where samples are tested in larger amounts above 50g and where the particles themselves can be affected by the test; it is anticipated that the small sample in the avalanche tester could be returned to a large bulk of powder or process after testing as it is unlikely to have been affected.

Clearly the use of avalanche testers is not new, and a thorough study of both free-flowing and cohesive powder behaviour in testers of this nature has been done by Alexander et al. [2], including the use of variants of lactose. However, the tester used had a diameter of $140 \mathrm{~mm}$ and a length of $420 \mathrm{~mm}$, compared to a diameter of $20 \mathrm{~mm}$ and length $35 \mathrm{~mm}$ in this study. Alexander et al. [2] demonstrated that free-flowing materials in avalanche showed a periodic behaviour at low agitation with a smoother, more continuous behaviour at high rotational speeds. Particles that were "drycohesive", where interparticle liquid bridges were not the main source of cohesion, showed more hysteresis and localised responses to agitation that did not show the periodic motion displayed by the 
free-flowing material. Other detailed studies using radioactive tracers by Ding et al. [3] and Lim et al. [4] have characterised lab-scale avalanche systems to examine slumping and rolling modes associated with rotary kiln driers, based on fundamental studies by Heinen et al. [5]. These modes are shown in Figure 3.

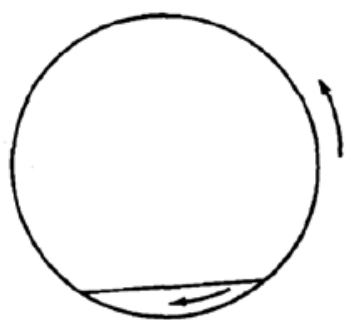

Slipping

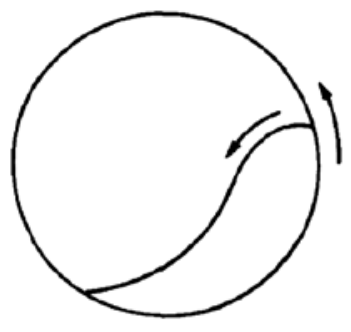

Cascading
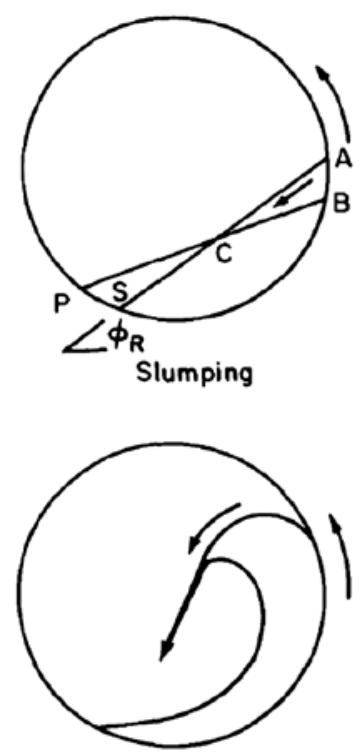

Cataracting

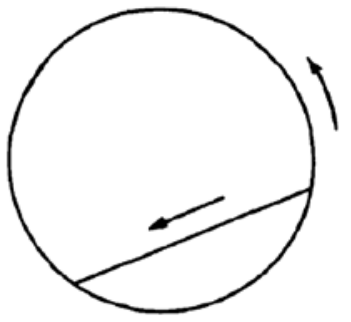

Rolling

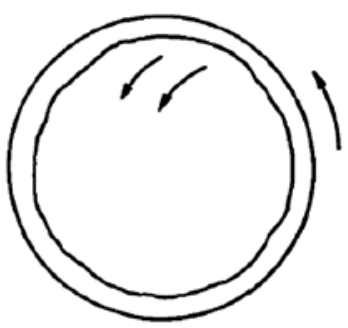

Centrifuging

Figure 3: Classifying particle motion in rotating drums [5].

Avalanche systems with extremely smooth interior surfaces show slipping behaviour, which is not normally observed. Normally at low rotating speeds, the bed adopts a "slumping" mode, where particles move up the side of the vial wall to the angle of repose; subsequently the bed of particles slumps to a lower angle. At faster speeds the bed reverts to a "rolling" mode, where it remains at a constant angle to the horizontal and powder grains cascade down the slope. Still higher speeds cause a distortion of this angled slope to cascading mode. Cataracting mode at speeds above this causes particle-air mixing. At the critical rotating velocity, the particles are forced to the wall of the drum in a centrifuge mode. This study will attempt to identify whether these types of behaviour exist in the context of a miniaturised and establish the conditions which favour them. This will be useful in assessing its suitability as a process analytical technology for high value pharmaceuticals. 


\section{MATERIALS AND METHODS}

\section{The Test Materials}

The test materials used are four versions of lactose used in pharmaceutical formulation, their properties were obtained using the appropriate British Pharmacoepia standard method and are summarised in Table 1 . The key particle sizes $d_{10}, d_{50}$ and $d_{90}$ for each of the powders are also shown in Table 2. The particle size distributions for the test powders are shown in Figure 4 and were obtained using a laser light scatter method (Sympatec). Figure 5a-d shows magnified images of the powdered particles Lactose, Lactohale LH100, Lactohale LH200 and Lactohale LH300 respectively. These were obtained using a digital biological microscope model BA310, manufactured by the Motic Corporation.

\begin{tabular}{|c|c|c|c|c|c|}
\hline Material & $\begin{array}{c}d_{50} \\
(\mu \mathrm{m})\end{array}$ & $\begin{array}{c}\text { Moisture } \\
\text { content } \\
(\%)\end{array}$ & $\begin{array}{l}\text { Angle of } \\
\text { repose }\left({ }^{\circ}\right)\end{array}$ & $\begin{array}{l}\text { Compressibility } \\
\text { Index (\%) }\end{array}$ & $\begin{array}{c}\text { Hausner } \\
\text { ratio }\end{array}$ \\
\hline $\begin{array}{c}\text { Lactose } \\
\text { (GSK) }\end{array}$ & $\begin{array}{l}62.34 \\
(0.08)\end{array}$ & $\begin{array}{c}1.47 \\
(0.15)\end{array}$ & $\begin{array}{l}43.18 \\
(0.79)\end{array}$ & $\begin{array}{l}18.30 \\
(0.78)\end{array}$ & $\begin{array}{c}1.22 \\
(0.01)\end{array}$ \\
\hline $\begin{array}{r}\text { LH100 } \\
\text { (DFE) }\end{array}$ & $\begin{array}{l}114.72 \\
(0.31)\end{array}$ & $\begin{array}{c}1.27 \\
(0.06)\end{array}$ & $\begin{array}{l}41.53 \\
(0.80)\end{array}$ & $\begin{array}{l}21.80 \\
(1.19)\end{array}$ & $\begin{array}{c}1.28 \\
(0.02)\end{array}$ \\
\hline $\begin{array}{l}\text { LH200 } \\
\text { (DFE) }\end{array}$ & $\begin{array}{l}47.11 \\
(0.53)\end{array}$ & $\begin{array}{l}1.17 \\
(0.15)\end{array}$ & $\begin{array}{l}53.01 \\
(0.53)\end{array}$ & $\begin{array}{l}36.37 \\
(0.66)\end{array}$ & $\begin{array}{c}1.57 \\
(0.02)\end{array}$ \\
\hline $\begin{array}{l}\text { LH300 } \\
\text { (DFE) }\end{array}$ & $\begin{array}{c}3.72 \\
(0.02)\end{array}$ & $\begin{array}{c}1.30 \\
(0.10)\end{array}$ & $\begin{array}{l}50.92 \\
(0.65)\end{array}$ & $\begin{array}{l}40.23 \\
(0.46)\end{array}$ & $\begin{array}{c}1.67 \\
(0.01)\end{array}$ \\
\hline
\end{tabular}

Table 1: A summary of the test material characteristic, presented as the average of 3 measurements \pm the standard deviation.

\begin{tabular}{|c|c|c|c|}
\hline Material & $\mathbf{d}_{\mathbf{1 0}}(\boldsymbol{\mu m})$ & $\mathbf{d}_{\mathbf{5 0}}(\boldsymbol{\mu m})$ & $\mathbf{d}_{\mathbf{9 0}}(\boldsymbol{\mu m})$ \\
\hline Lactose (GSK) & $28.20(0.09)$ & $62.34(0.08)$ & $81.10(0.04)$ \\
\hline Lactohale LH100 & $37.09(0.4)$ & $114.72(0.31)$ & $157.36(0.16)$ \\
\hline Lactohale LH200 & $4.70(0.14)$ & $47.11(0.53)$ & $75.45(0.17)$ \\
\hline Lactohale LH300 & $0.98(0.02)$ & $3.72(0.02)$ & $8.81(0.03)$ \\
\hline
\end{tabular}

Table 2: Particle size characteristics for the test powders, obtained from laser light scattering (Sympatec). The values are the arithmetic mean of 3 samples, with the standard deviation in brackets.

\section{Obtaining the Flow Function of the Test Materials Using the Brookfield Powder Tester}

The flow function of each of the powders was obtained using the Brookfield powder tester at a relative humidity of $35-40 \%$ and a temperature of $20-25^{\circ} \mathrm{C}$ [6]. Fresh samples were used for each test, 
with three repetitions performed for each powder. Figure 6 is a plot of unconfined failure strength $\sigma_{c}$ against the major principle consolidation stress $\sigma_{1}$, with the gradient being the flow function as defined by Woodcock and Mason [7]. Simple regression analysis of the scatter plots showed a consistent trend and the values for each powder are given in Table 3.

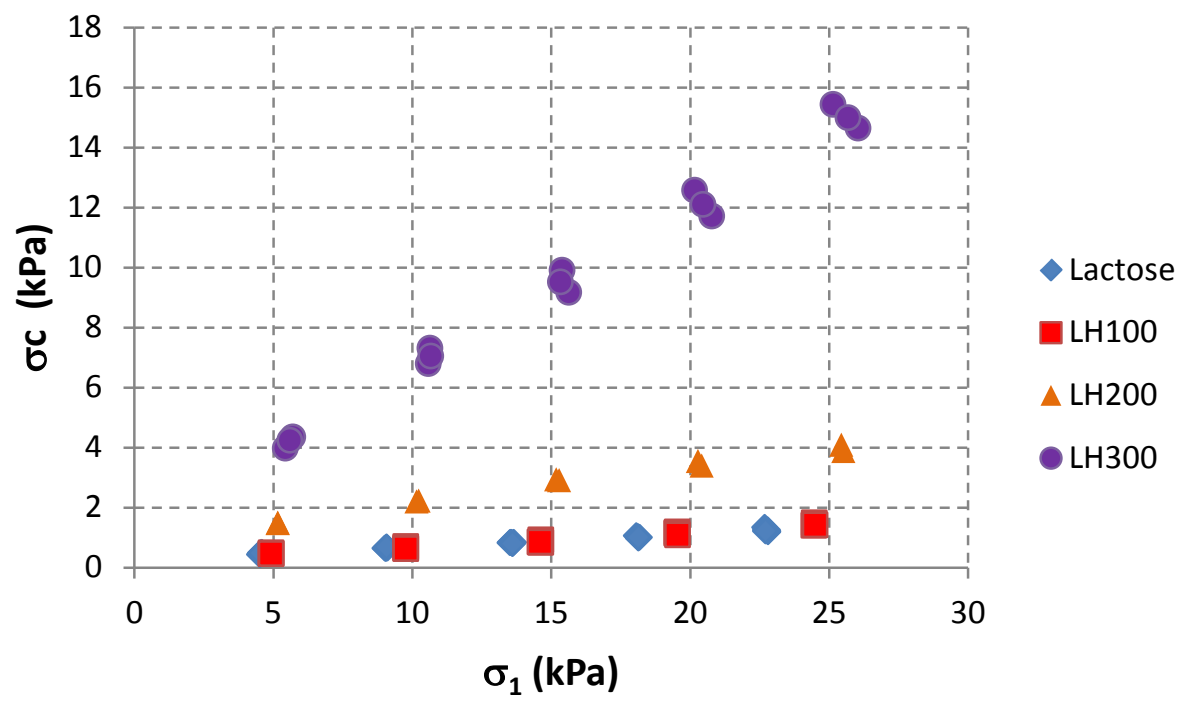

Figure 6: A plot of unconfined failure strength $\sigma_{\mathrm{c}}$ against the major principle consolidation stress $\sigma_{1}$ in kPa for lactose, LH100, LH200 and LH300.

\begin{tabular}{|c|c|c|c|}
\hline & $\begin{array}{c}\text { Gradient (Flow } \\
\text { Function) }\end{array}$ & Intercept & $\mathrm{R}^{2}$ \\
\hline Lactose & 0.0422 & 0.2634 & 0.9853 \\
\hline Lactohale LH100 & 0.0494 & 0.1923 & 0.9821 \\
\hline Lactohale LH200 & 0.1233 & 0.9272 & 0.9880 \\
\hline Lactohale LH300 & 0.5345 & 1.2740 & 0.9900 \\
\hline
\end{tabular}

Table 3: A summary of the data obtained in Figure 6, comparing the flow properties of the four test materials.

\section{The Avalanche Test Conditions}

The Ingham Group avalanche tester was used with fixed illumination and version 1.1.0 software. Speeds were set as required and the supplied glass $20 \mathrm{~mm}$ diameter glass vessel used in all cases. The vessel was half-filled with test powder, giving a net mass of $3 \mathrm{~g}$, sealed and placed on the rotating system in preparation for testing. The rate of rotation was set to 20 revolutions per minute $(0.33 \mathrm{~Hz})$ which was confirmed through image analysis. Data was gathered over a 52 second period once at speed in each case and transferred to an excel spreadsheet for further analysis. Subsequent tests involved increasing the rotational frequency to $0.66 \mathrm{~Hz}$ and $1.1 \mathrm{~Hz}$. 


\section{RESULTS AND DISCUSSION}

The measured flow function values (Table 3) are consistent with a previous study using lactose by Saw et al. [8]. The fine particles of LH300 gave the most cohesive powder with a flow function almost an order of magnitude higher than powders Lactose and LH100. Despite clear differences between the particle size, shape and degree of polydispersity of Lactose and LH100, the two powders have very close flow functions. From these results LH300 would be classified as very cohesive, LH200 as "easy flowing" and the other powders as "free flowing".

Figures 7 and 8 compare the avalanche $\mathrm{X}$ and $\mathrm{Y}$ co-ordinates respectively for each of the powders, based on deviation around the average. The results show a periodic motion in the free-flowing LH100, as expected from the study by Alexander et al. [2], with a turnover time of approximately 5 seconds. However, there is no clear periodic behaviour in the other samples. Figure 9 shows the coupling between the $\mathrm{X}$ and $\mathrm{Y}$ coordinates, consistent with previous studies as a slumping motion [2,5].

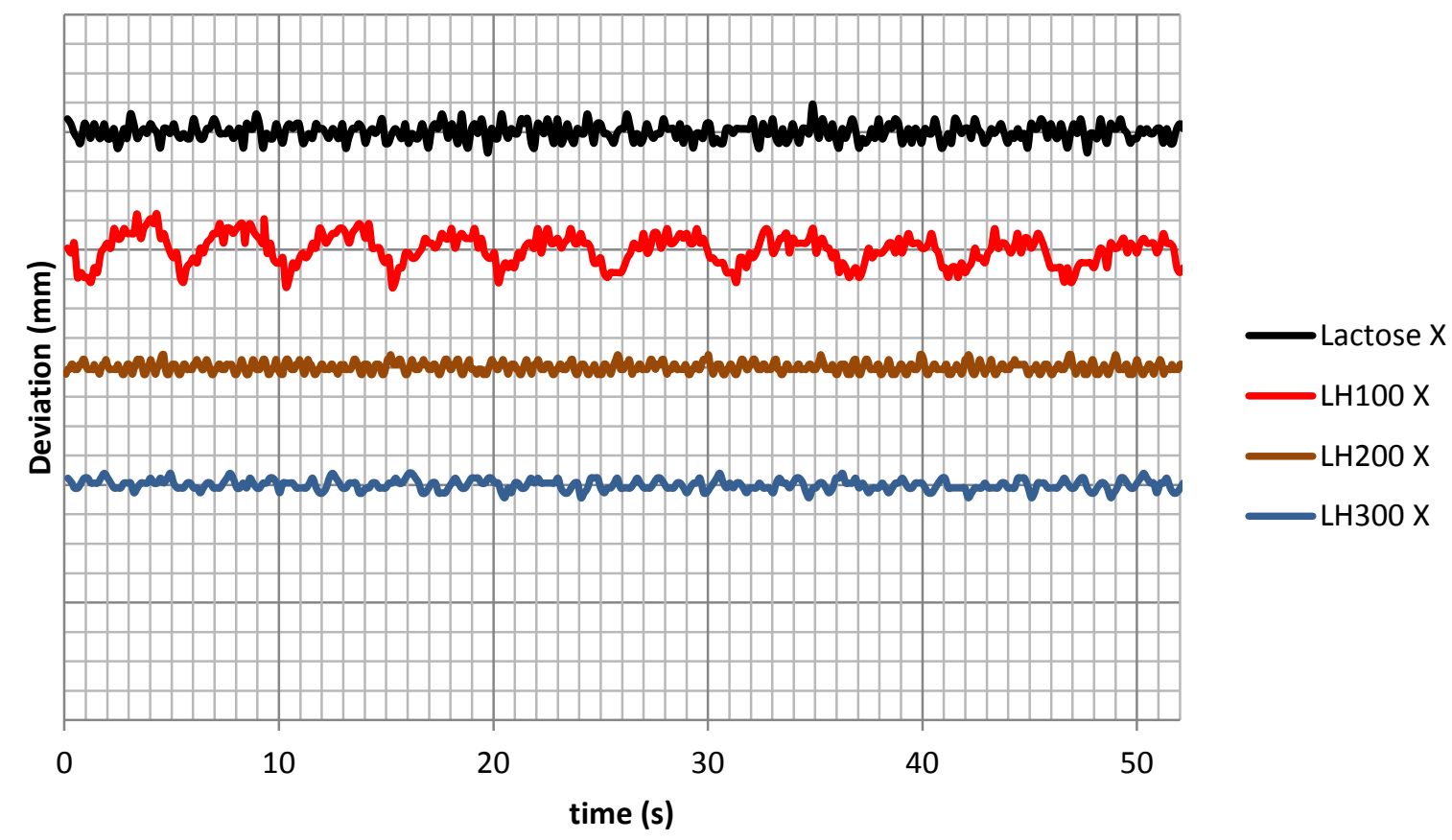

Figure 7: $\quad$ Comparing the $X$ deviation in $\mathbf{m m}$ around the average $X$ value for the four test materials at a rotation speed of 20 revolutions per minute $(0.33 \mathrm{~Hz})$. Each division on the $y$-axis represents $0.5 \mathrm{~mm}$. 


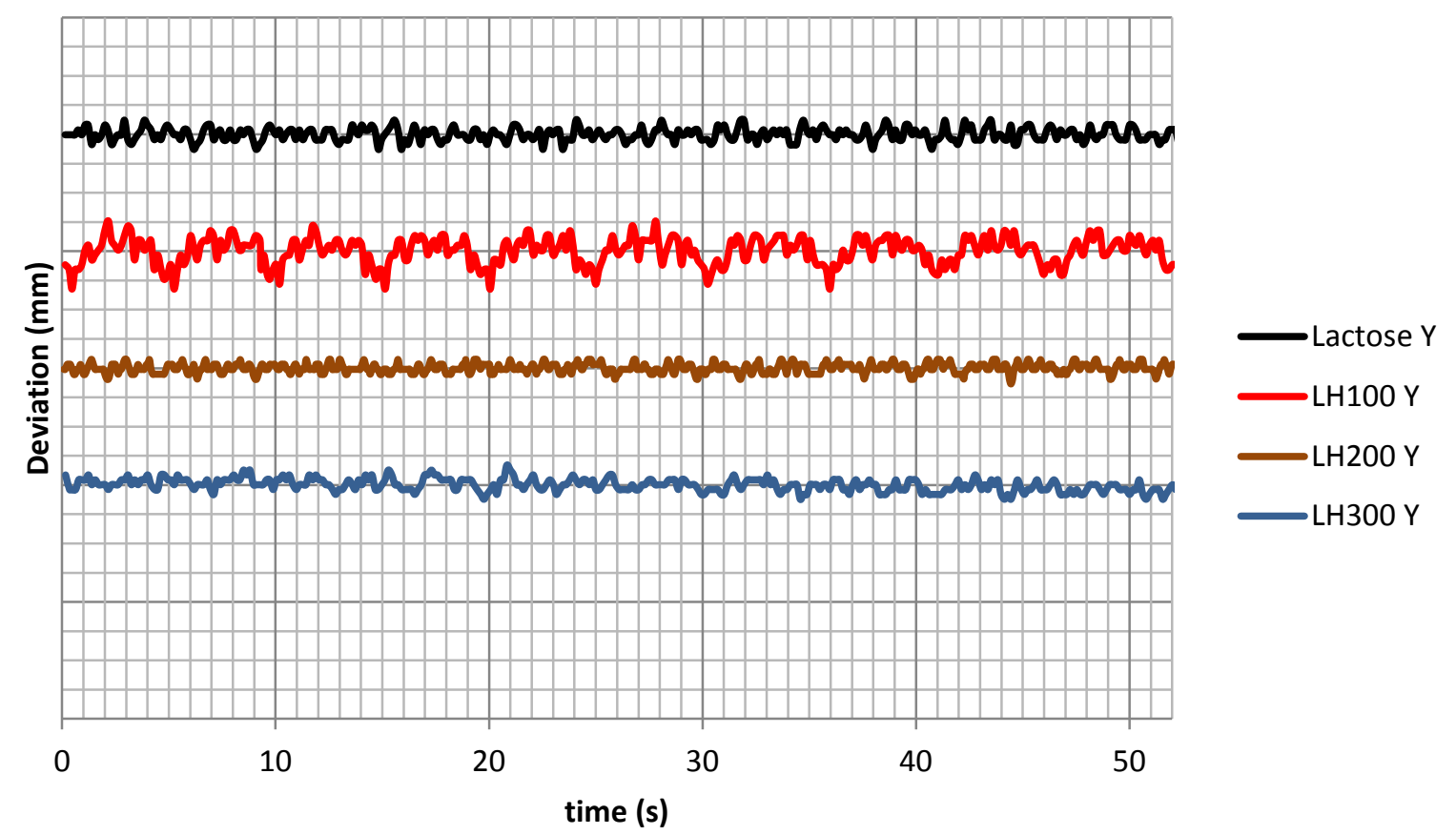

Figure 8: Comparing the $\mathrm{Y}$ deviation in $\mathrm{mm}$ around the average $\mathrm{Y}$ value for the four test materials at a rotation speed of 20 revolutions per minute $(0.33 \mathrm{~Hz})$. Each division on the $y$-axis represents $0.5 \mathrm{~mm}$.

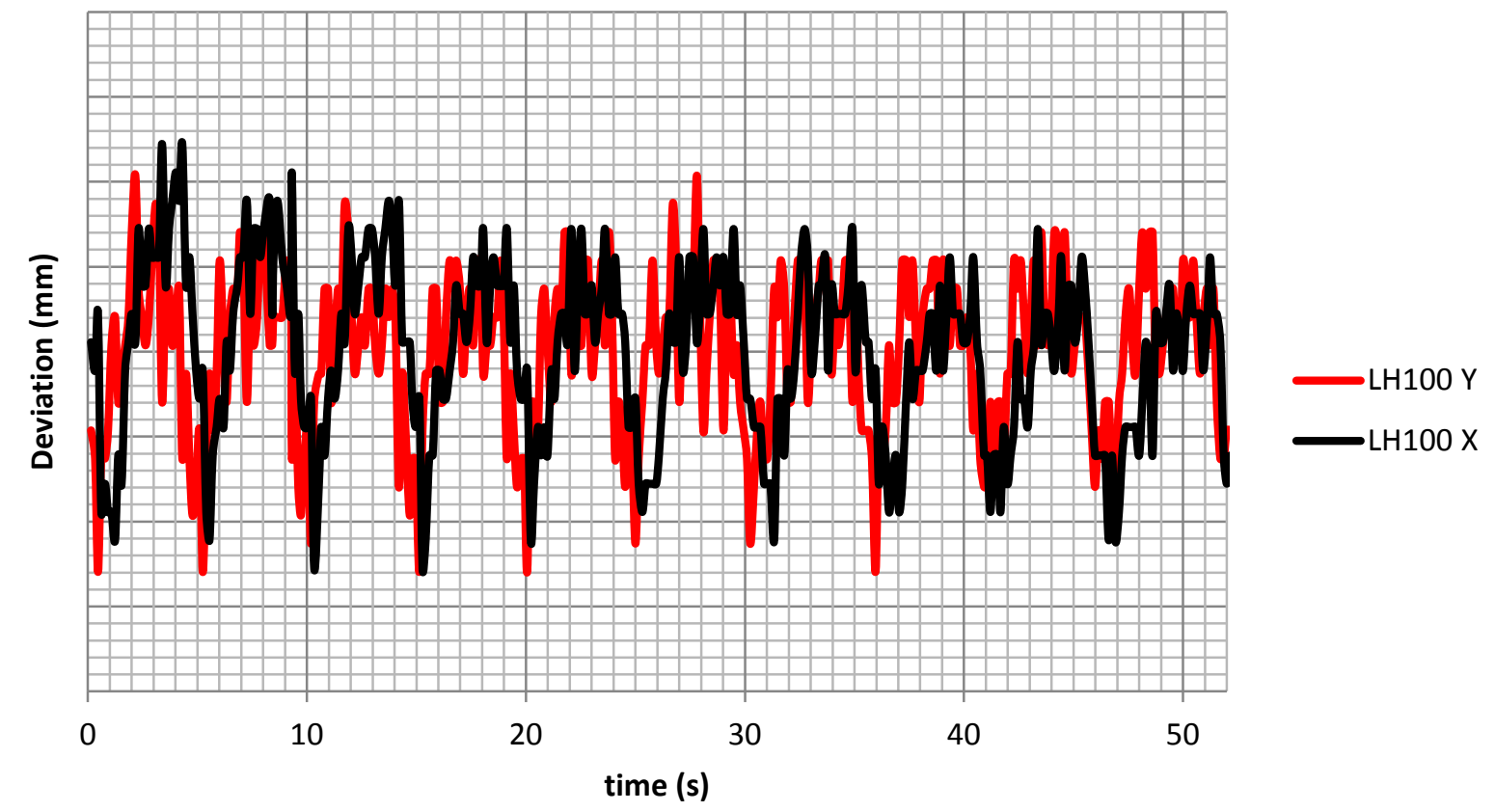

Figure 9: $\quad$ Comparing the $\mathrm{X}$ and $\mathrm{Y}$ deviations in $\mathrm{mm}$ around the average value for $\mathrm{LH100}$ at a rotation speed of 20 revolutions per minute $(0.33 \mathrm{~Hz})$. Each division on the y-axis represents $0.05 \mathrm{~mm}$.

The experiment was repeated with LH100 at the increased drum rotation speeds of 36 revolutions per minute $(0.66 \mathrm{~Hz})$ and 66 revolutions per minute $(1.1 \mathrm{~Hz})$ to see whether this coupled behaviour would persist, or, as anticipated by previous studies [2], reduce significantly. Figure 10 shows the comparison between the X and Y coordinates for LH100 at $0.33 \mathrm{~Hz}, 0.66 \mathrm{~Hz}$ and $1.1 \mathrm{~Hz}$. In order to 
highlight any patterns, the time has been normalised by multiplying it by the rotation frequency divided by $0.33 \mathrm{~Hz}$.

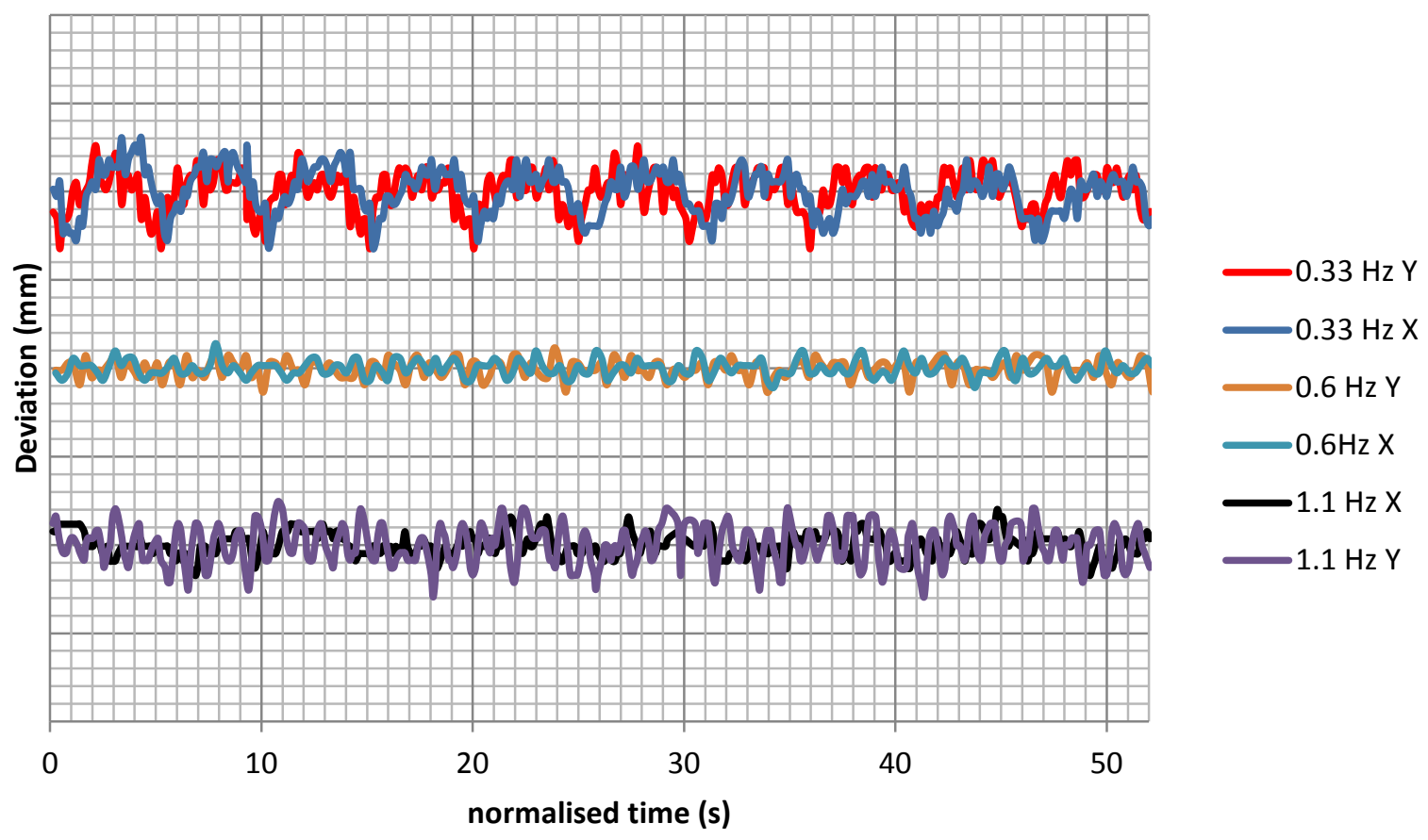

Figure 10: Comparing the $X$ and $Y$ deviations in $\mathbf{m m}$ around the average value for $L H 100$ at a rotation speed of 20 revolutions per minute $(0.33 \mathrm{~Hz}), 36$ revolutions per minute $(0.6 \mathrm{~Hz})$ and 66 revolutions per minute $(1.1 \mathrm{~Hz})$. Each division on the $y$-axis represents $0.05 \mathrm{~mm}$.

By effectively doubling the rate of drum rotation from $0.33 \mathrm{~Hz}$ to $0.6 \mathrm{~Hz}$, the motion of the particles becomes completely decoupled from the drum rotation and shows little deviation, as predicted by previous studies. When the rate of rotation is increased still further to $1.1 \mathrm{~Hz}$, the particles become more agitated and show significant deviation, particularly in the $\mathrm{Y}$ direction, but this is unrelated to motion in the $\mathrm{X}$ direction. These results suggest a transition initially to rolling motion at $0.6 \mathrm{~Hz}$ and then a cascading or cataracting motion at $1.1 \mathrm{~Hz}$.

A more detailed analysis of the data using Fast Fourier analysis confirmed the unique behaviour of LH100 with respect to the other powders, particularly with respect to the variation in the X direction. Figure 11 compares spectra for each of the powders with respect to deviation in the $\mathrm{X}$ direction at $0.33 \mathrm{~Hz}$. 


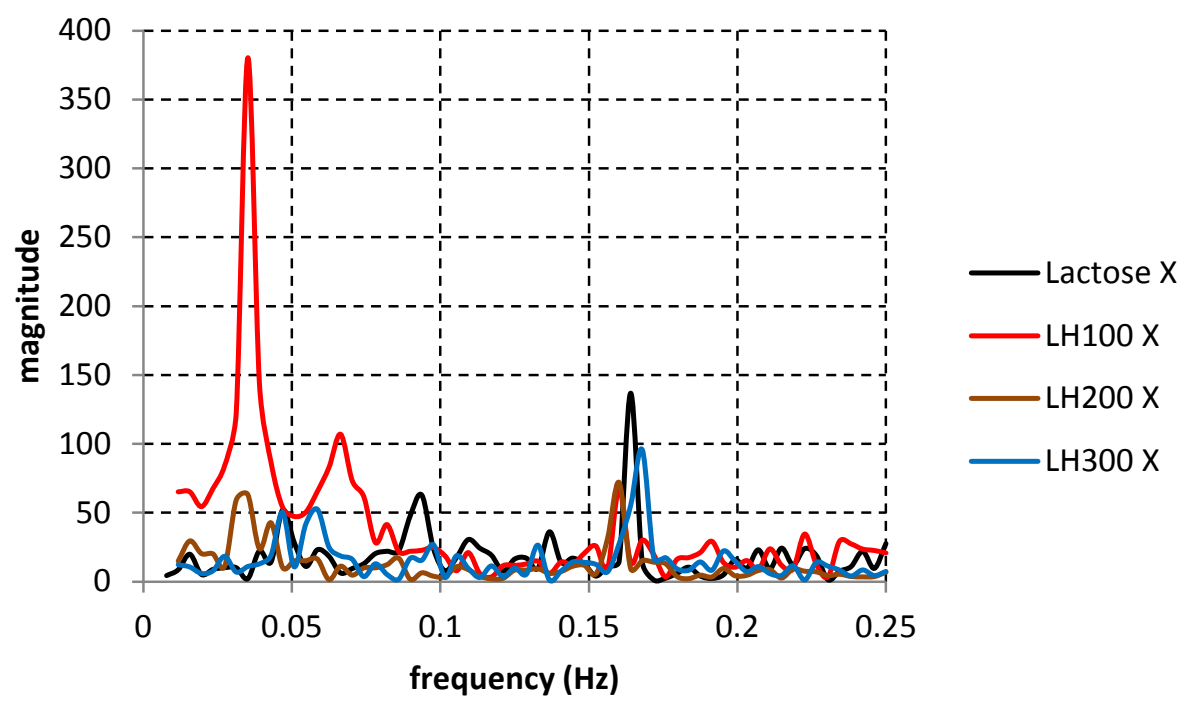

Figure 11: Fast Fourier plot of the $\mathrm{X}$ deviation for the test powders at rotation $0.33 \mathrm{~Hz}$.

LH100 shows a large peak at $0.035 \mathrm{~Hz}$, suggesting a cycle that takes 10 revolutions of the vial, consistent with a slumping sequence. All powders have a smaller peak at approximately $0.065 \mathrm{~Hz}$, i.e. $\mathrm{f} / 2$. This shows that the vial is not a perfect cylinder and shows a slight shift at every half rotation. This peak is also visible in the equivalent Y-deviation plot in Figure 12, but to a lesser extent. Again the LH100 shows a peak at low frequencies, this time at around $0.02 \mathrm{~Hz}$.

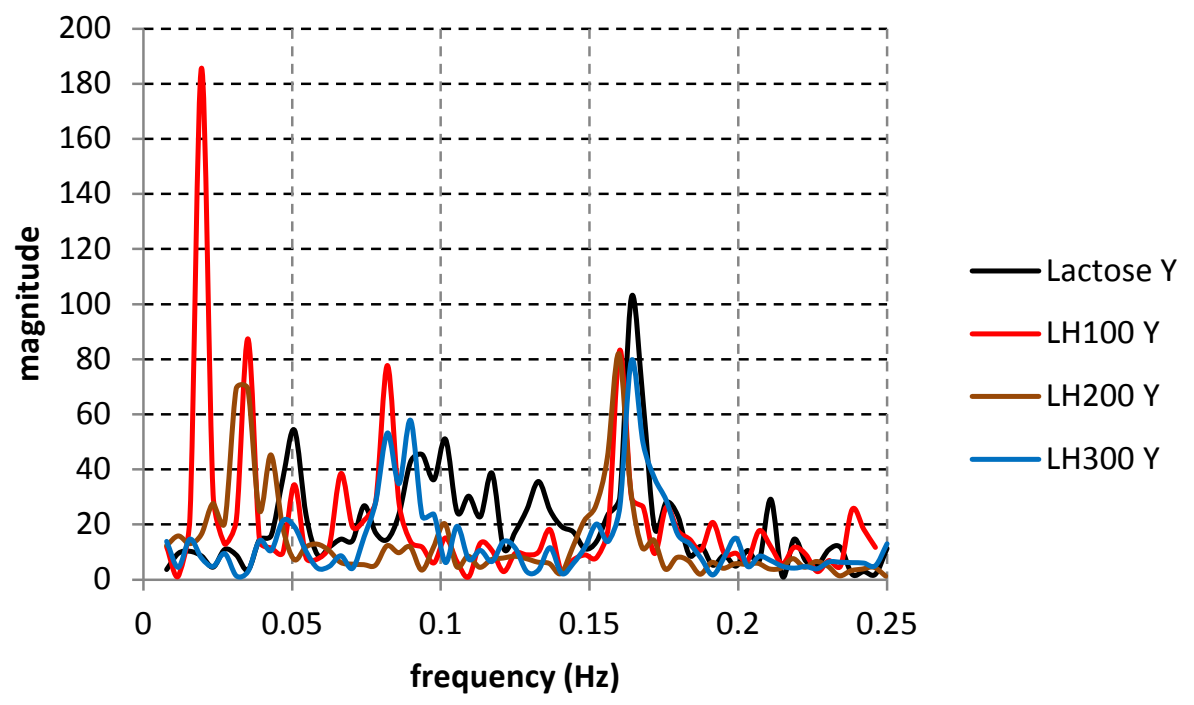

Figure 12: Fast Fourier plot of the $Y$ deviation for the test powders at rotation $0.33 \mathrm{~Hz}$.

Fast Fourier analysis of the data for LH100 systems being rotated at 0.33, 0.6 and $1.1 \mathrm{~Hz}$ shows that the peak in the $\mathrm{X}$ displacement disappears as the vial rotation speed is increased, as shown in Figure 13.The distinct peaks in the Y displacement of LH100 rotating at $0.33 \mathrm{~Hz}$ disappear at $0.6 \mathrm{~Hz}$, only to return at a different frequency at $1.1 \mathrm{~Hz}$, as shown in Figure 14. This suggests a significant distortion of the bed at $1.1 \mathrm{~Hz}$ and supports the idea of cascading and cataracting behaviour. 


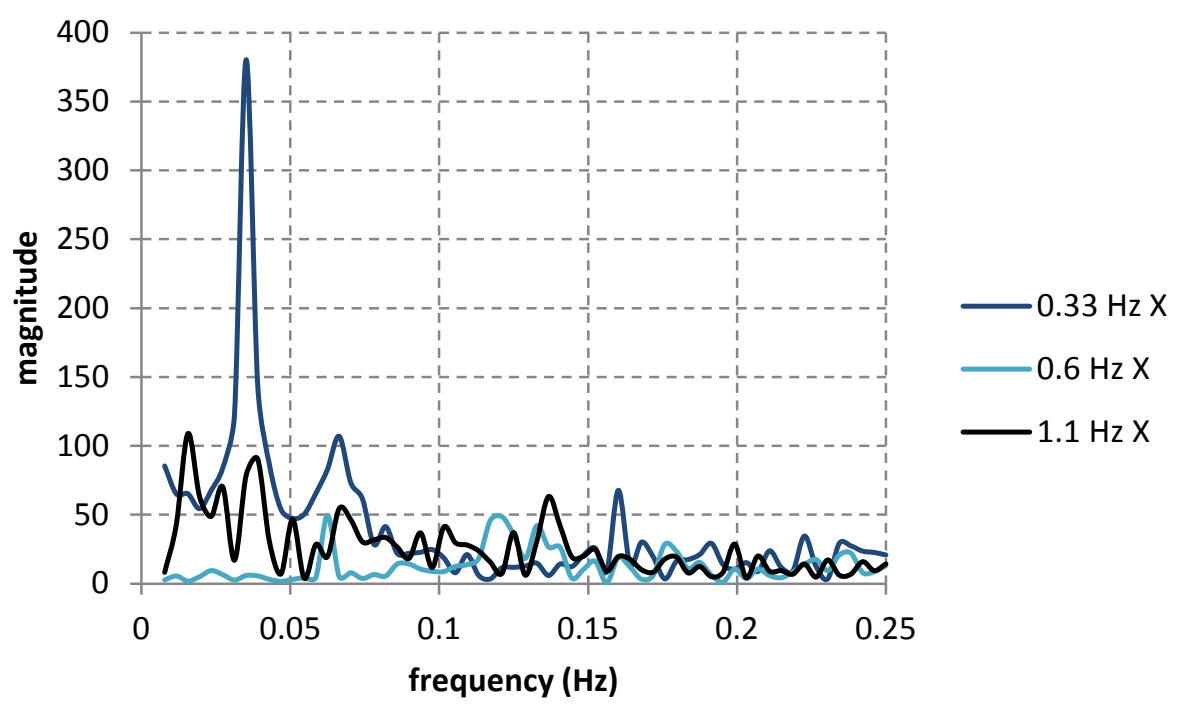

Figure 13: Fast Fourier plot of the $X$ deviation for $\mathrm{LH100}$ at $0.33 \mathrm{~Hz}, 0.6 \mathrm{~Hz}$ and $1.1 \mathrm{~Hz}$.

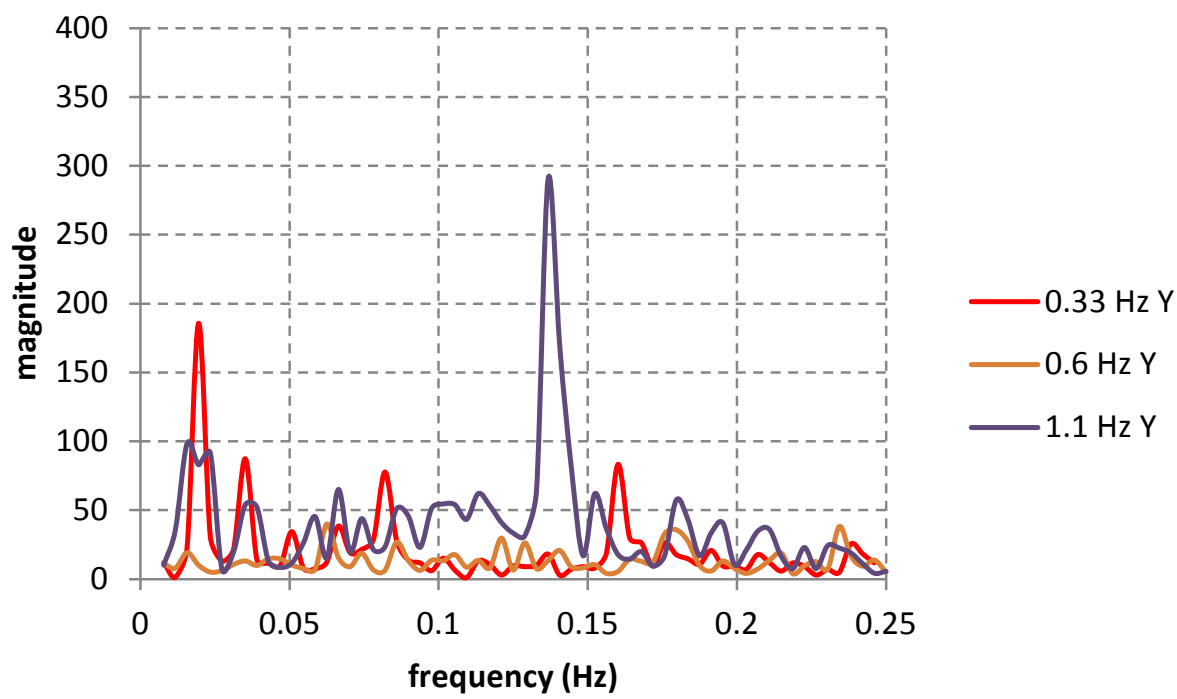

Figure 14: Fast Fourier plot of the $Y$ deviation for $\mathrm{LH100}$ at $0.33 \mathrm{~Hz}, 0.6 \mathrm{~Hz}$ and $1.1 \mathrm{~Hz}$.

At the low rotational frequency of $0.33 \mathrm{~Hz}$, LH100 displays behaviour distinct from the other powders under the same conditions, being strongly influenced by the angular particle shape and wide size distribution. The flow function test based on a static sample does not differentiate significantly between the lactose (GSK) and the LH100 (DFE), despite very different behaviour under the dynamic conditions of the avalanche tester. However, the more cohesive materials LH200 and LH300 gave expected flow functions and also showed little deviation in the avalanche tester, suggesting that the avalanche test could quantify the cohesive nature of a small powder sample.

\section{CONCLUSION}

The complex motion of particles in a rotating vial is not solely influenced by interparticle forces and cohesiveness, as particle shape and polydispersity also cause variation in behaviour. The flow function measured by a shear cell will also not always indicate the behaviour of a powder in a dynamic system such as an avalanche tester. However, modes of particle motion present in larger 
avalanche systems are duplicated at this small scale and allow some qualitative assessment to be made of the flow properties of small samples, based on a free-flowing/cohesive criterion. We have illustrated how a low volume system can be used for fast screening of powders producing results comparable with those using larger volumes. Further work is being undertaken on irregular shaped particles to ascertain how significantly shape affects the behaviour in a rotating system. Comparison with other dynamic particle flow measuring systems, such as the Freeman FT4, will also be necessary.

\section{REFERENCES}

1. Ekenlebie, E.P, Pharmaceutical process optimisation of bulk lyophilisates, PhD Thesis, School of Pharmacy, Aston University, Birmingham, UK, 2014.

2. Alexander, A.W.; Chaudhuri, B.; Faqih, A.; Muzzio, F.J.; Davies, C.; Tomassone, M.S. Avalanching flow of cohesive powders. Powder Technology, 2006, 164, 13-21.

3. Ding, Y.L.; Forster, R.N.; Seville, J.P.K.; Parker, D.J. Granular motion in rotating drums: bed turnover time and slumping-rolling transition. Powder Technology, 2002, 124, 18-27.

4. Lim, S.Y.; Davidson, J.F.; Forster, R.N.; Parker, D.J.; Scott, D.M.; Seville, J.P.K. Avalanching of granular material in a horizontal slowly rotating cylinder: PEPT studies. Powder Technology, 2003, 138, 25-30.

5. Heinen, H.; Brimacombe, J.K.; Watkinson, A.P. Experimental study of transverse bed motion in rotary kilns. Metallurgical Transactions B, 1983, 14B, 191-205.

6. Berry, R.J.; Bradley, M.S.A. Investigation of the effect of test procedure factors on the failure loci and derived failure functions obtained from annular shear cells. Powder Technology, 2007, 174, 60-63.

7. Woodcock, C.R.; Mason, J.S. Bulk Solids Handling, 1987. ISBN 0-412-01251.

8. Saw, H.G.; Davies, C.E.; Jones, J.R.; Brisson, G.; Paterson A.H.J. Cohesion of lactose powders at low consolidation stresses. Advanced Powder Technology, 2013, 24, 796-800. 